\title{
TIPOS Y CARACTERISTICAS DE EJES URBANOS DE LA CIUDAD DE RESISTENCIA SEGÚN SU ARBOLADO
}

CATEGORIES AND FEATURES OF URBAN HUBS IN THE CITY OF RESISTENCIA ACCORDING TO TREE GROWTH

\section{GONZÁLEZ, Walter A.}

Alumno becario de Investigación. F.A.U. U.N.N.E. Este trabajo forma parte de los resultados de la investigación realizada como parte del Plan de Beca de Pregrado de la SGCYT_UNNE (2011-2012) "Identificación y Caracterización de las Topologías de Ejes Urbanos de la Ciudad de Resistencia Teniendo en Cuanta sus Áreas Verdes y su Forestación" Direc. Laura Alcalá. Un avance de este trabajo fue publicado en libro en libro Comunicaciones Científicas y Tecnológicas 2011 EDIFAU. Facultad de Arquitectura y Urbanismo. UNNE. 2012. ISSN1666-4035. E-mail: walter_ar_q@hotmail.com.

Palabras Clave: Espacio público - forestación - paisaje urbano

Keywords: Public spaces - forestation - urban landscape

\section{RESUMEN}

La constatación de la pérdida de los atributos paisajísticos en la Ciudad de Resistencia en las áreas de nuevo desarrollo así como la degradación sistemática del área central por reducción de la superficie verde y la falta de políticas de reforestación y de criterios acertados para hacerlo vuelven necesario realizar un estudio exploratorio que permita identificar las mejores situaciones ambientales y paisajísticas, estudiarlas y tipificarlas, a fin de ponerlas en valor, y contar con criterios claros para proponer a futuro criterios de forestación y de intervención en las superficies verdes del espacio público.

\section{ABSTRACT}

Having seen confirmation of loss of landscape attributes in areas of recent development on the city of Resistencia as well as a systematic degradation of the center area due to the reduction of green spaces and the lack of reforestation policies and suitable criteria for the undertaking of it, it has been rendered necessary to carry out an exploratory study to identify the best environmental and landscape settings, to study them and categorize them in order to foster them and have a clear criteria to propose future criteria for forestation and action on public green spaces. 


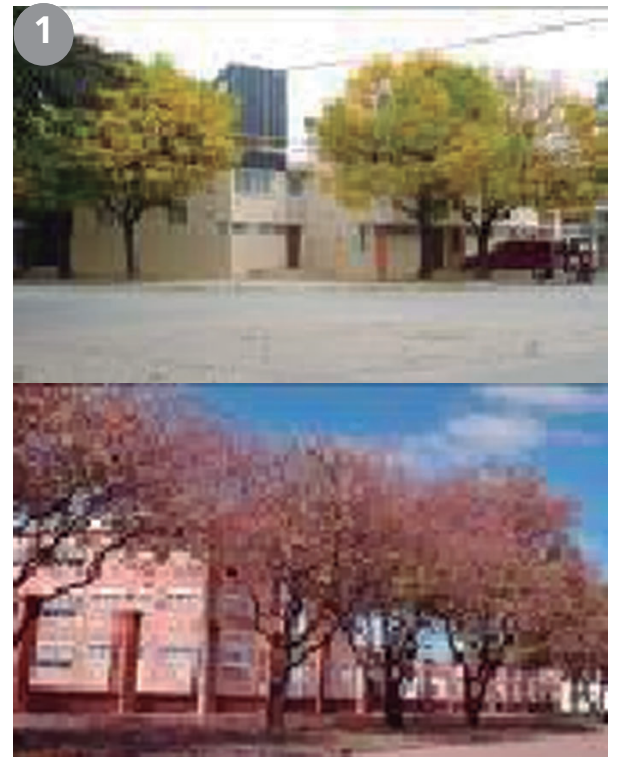

\section{OBJETIVO}

\section{Objetivo General}

- Contribuir a la identificación y caracterización de las tipologías de ejes urbanos del área central de Resistencia teniendo en cuenta sus superficies verdes y su forestación, sus potencialidades paisajísticas y ambientales.

\section{Objetivos secundarios}

- Conceptualizar las nociones de paisaje y calidad ambiental en relación al espacio público.

- Contribuir a los objetivos del PI SGCYT C001/08 Res. C. S. 831 /08 Espacio Público en el Gran Resistencia. Diagnóstico y Propuesta para el mejoramiento integral del sistema de calles.

\section{INTRODUCCIÓN O PLANTEO DEL PROBLEMA}

Se observa en la ciudad de Resistencia una belleza paisajística en las diferentes épocas del año, en donde la ciudad se tamiza con diferentes colores, olores y hasta se puede decir diferentes sensaciones. El arbolado urbano le da estas características muy poco potenciadas, las cuales embellecen a la ciudad generando recorridos agradables y de fuerte impacto visual en los habitantes, tanto en los residentes comunes como en los visitantes, este es el motivo por el cual se genero la investigación y el origen de la beca, la intención de ir mas a fondo en el conocimiento de las especies arbóreas que se encuentran en la ciudad, y la calidad ambiental y estética que estas ofrecen, aportando una caracterización con la cual se pueda tipificar los ejes y recorridos urbanos que se encuentran en ella a fin de poder estudiarlos y analizarlos, encontrando en los mismos aspectos negativos (para llegar a salvarlos) y aspectos positivos (para poder potenciarlos si fuese necesario), así también para poder entender aun mejor el estado del arbolado de la ciudad, y cuales son sus falencias mas comunes.

Para el trabajo de tipificación se tomaron ejes representativos dentro de un sector de la trama de la ciudad elegida, la cual corresponde a la parte central, donde se ven con mejor claridad los diferentes casos; extremos desde el punto de vista negativo, como los mas factibles y de ejemplos a seguir, con respecto al estado del arbolado y del paisaje urbano con todos sus elementos. Con el levantamiento de esta información in situ se comenzó la investigación, llegando a las conclusiones y comentarios que se detallaran más adelante. (Fig. 1).

\section{DESARROLLO}

El trabajo de campo fue realizado tomando muestras de ejes urbanos representativos dentro de la trama de la ciudad de Resistencia, estas muestras se ubican dentro del anillo central de la misma comprendido dentro del cuadrante delimitado por las Avenidas Castelli - Alvear; Las heras - Velez Sarfield; Laprida - Lavalle y Avalos - Hernandarias; tomando a estas como limite, por ser donde el área de la ciudad esta mas consolidada y se ve mejor la degradación de la misma por no respetar las normativas vigentes para el desarrollo del espacio publico, hablando claro de los espacios destinados para canteros y las dimensiones obligatorias que estos debieran tener para el desarrollo y la subsistencia de las especies arbóreas como así también las medidas a respetar de anchos de calzada, etc. (Fig. 2 y 3 ).

Siguiendo con el trabajo realizado in situ, o sea 


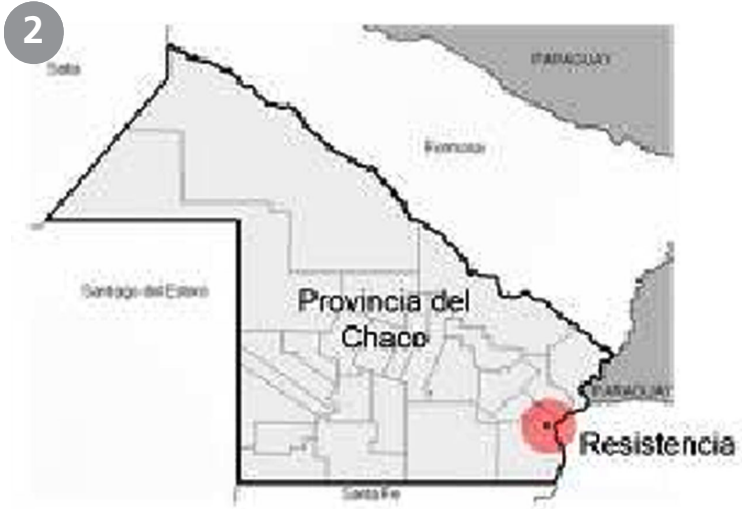

el trabajo de la toma de muestras para verificar y analizar diferentes factores dentro de la urbe Resistenciana, teniendo como protagonista principal el paisaje urbano, se trabajo en conjunto con la Directora de beca, para seleccionar cuales serian las muestras mas distintivas para lograr un estudio fehaciente y que sirva para llegar a cubrir los objetivos planteados. En la selección se tuvo en cuenta la experiencia personal y la vivencia desarrollada como usuarios y residentes activos de Resistencia, así también la experiencia en investigaciones realizadas por el PI (donde se inserta esta investigación). Para volcar la información recolectada se realizo una ficha de relevamiento en donde se introdujeron los datos que sirvieron de ayuda para el reconocimiento del eje seleccionado, el mismo es un muestreo de $100 \mathrm{~m}$ de longitud, equivalente a un cuadra, en donde el objetivo principal era verificar la cantidad de especies que se hallan en el mismo a cada lado en las calzadas y ver el comportamiento de estas en las diferentes épocas del año, y como el paisaje urbano va cambiando, ya sea desde el punto de vista morfológico, como así también los diferentes cambios de colores y olores preceptúales que se generan en cada estación.

También se introdujo un plano de la ubicación del muestreo con respecto a la ciudad y un corte esquemático para analizar el entorno donde se desarrolla este.

Se relevo además la superficie absorbente destinada a los canteros, su infraestructura y el estado del verde superficial, datos de los cuales se verán luego si se ajustan a normativa o no, y como esto afecta al estado urbano-ambiental de la ciudad.

Se efectuaron tomas fotográficas en cada eje, para ir generando la base de datos que ejemplifique el estado de cada cuadra, donde se ven los cambios que se producen en el paisaje de la ciudad, como este posee o no un gran potencial paisajístico, y para reconocer también las especies que hacen la diferencia en dicho eje y que le dan los cambios que veníamos mencionando. Estas tomas se

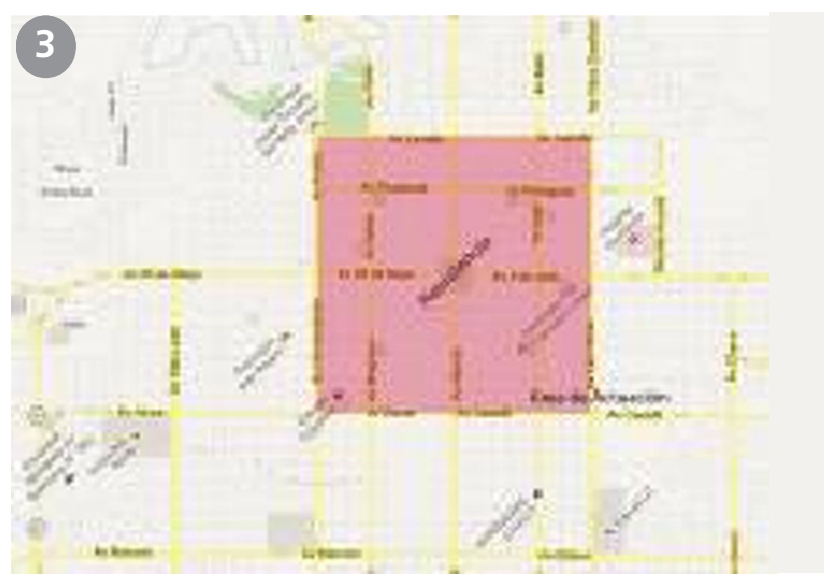

encuentran dispersas en cuatro puntos distintos, los cuales se eligieron por ser los más representativos y mas factibles para poder luego sacar conclusiones que ayuden a caracterizar y tipificar cada muestra con respecto a otras. Se volcó en la misma ficha asimismo la fecha o estación del año donde se realizo la toma fotográfica para tener un control mas preciso del eje relevado y de su estado en dicha estación. Se le dedico un sector para colocar algunas observaciones relevantes si fuera necesario, con el fin de ir teniendo en cuenta cualquier cambio notable de interés que ayude al análisis del sector que se estudia.

\section{FICHA DE RELEVAMIENTO IN SITU CARACTERÍSTICAS GENERALES DE LA}
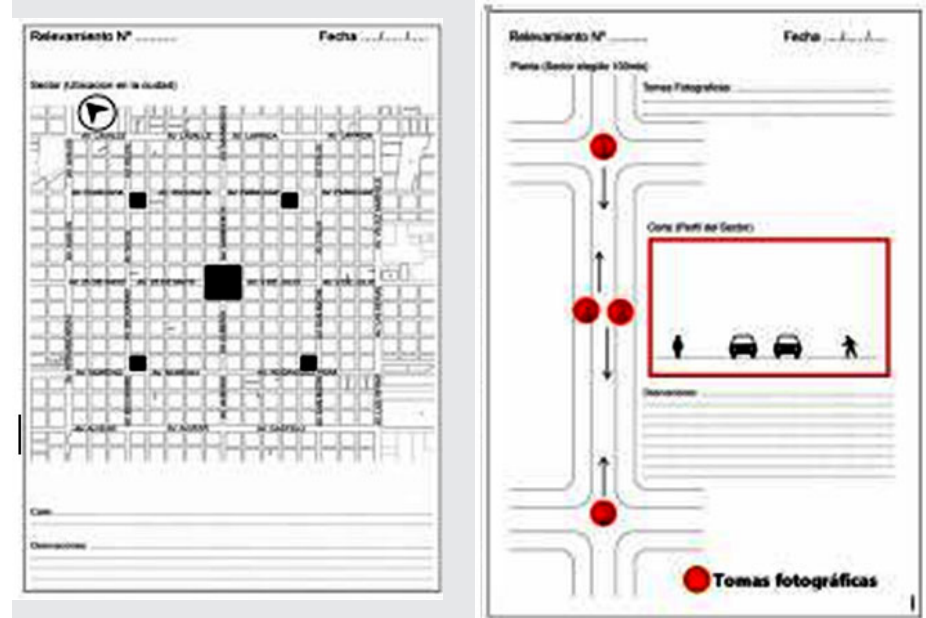

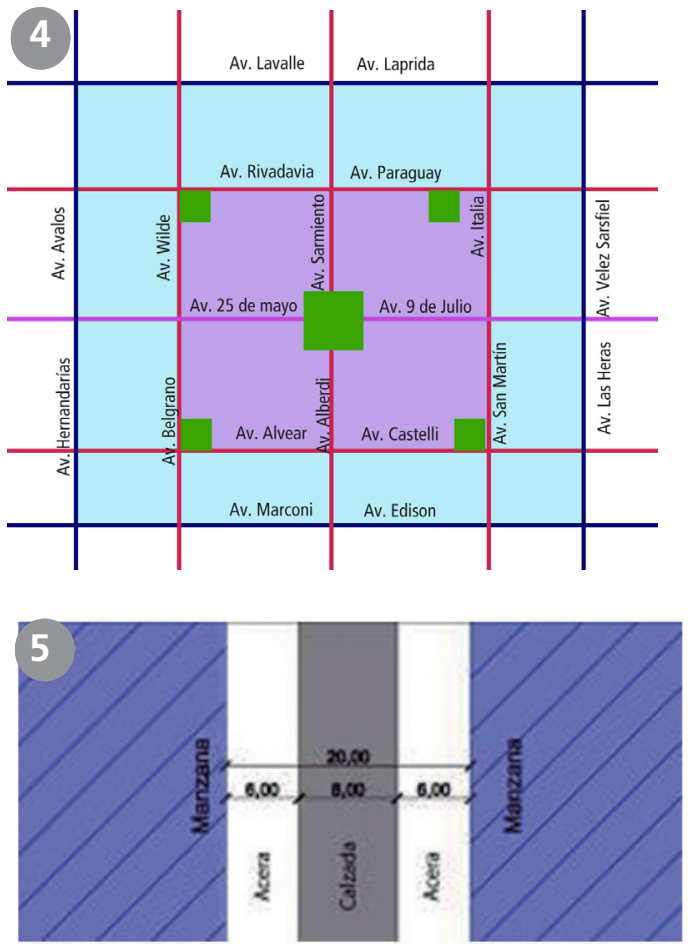

Medidas de calle Ancho total $20 \mathrm{mts}$

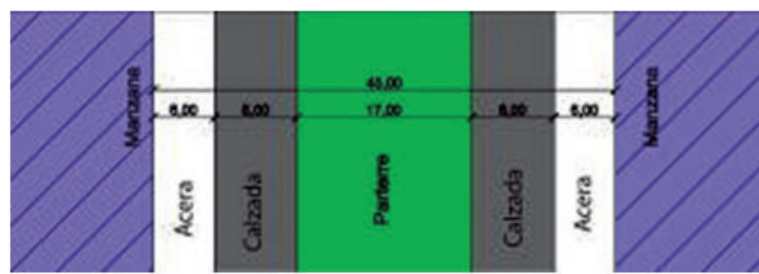

Avenida de $45 \mathrm{mts}$ y parterre de $17 \mathrm{mts}$.

\section{GRILLA URBANA Y DEL ESPACIO PÚBLICO DE LA CIUDAD DE RESISTENCIA}

De la grilla urbana de la ciudad, se puede decir que esta organizada desde un punto central (Plaza 25 de Mayo) desde donde parten cuatro avenidas principales a modo de ejes cartesianos, que organizan todo el sistema de calles y avenidas, de una trama regular de $100 \times 100$. Esta área central fundacional está rodeada por avenidas de $45 \mathrm{~m}$ que conforman un anillo de circunvalación que define el cuadrante central de la ciudad. Este cuadrante cuenta además con avenidas intermedias de $30 \mathrm{~m}$ en cuyas intersecciones se localizan cuatro plazas. Este cuadrante altamente regular definido por una trama donde el resto de las calles son de $20 \mathrm{~m}$ de ancho es donde se realizo el estudio de investigación sobre el arbolado urbano.

El sistema de avenidas, por el ancho y forestación que poseen, conforma corredores verdes que en el caso de las avenidas de circunvalación se complementa con la presencia de 2 de los parques urbanos, la Laguna Argüello y el Parque 2 de Febrero.
5. Variables del paterre

6. Veredas en general
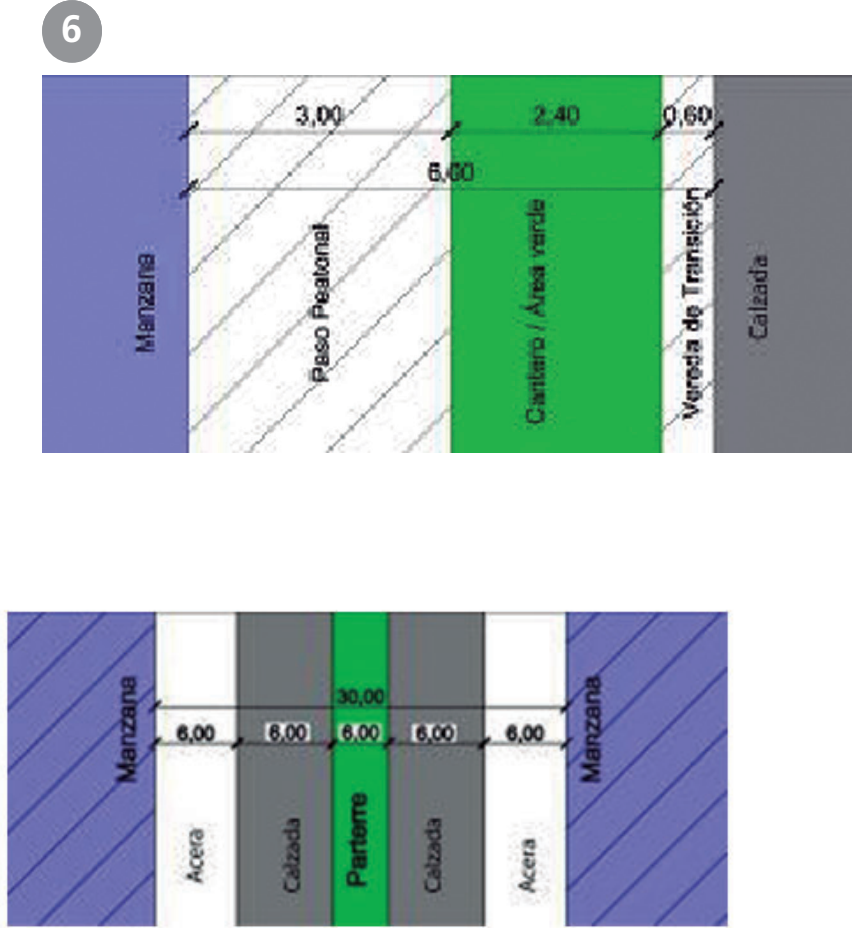

Avenidas de $30 \mathrm{mts}$

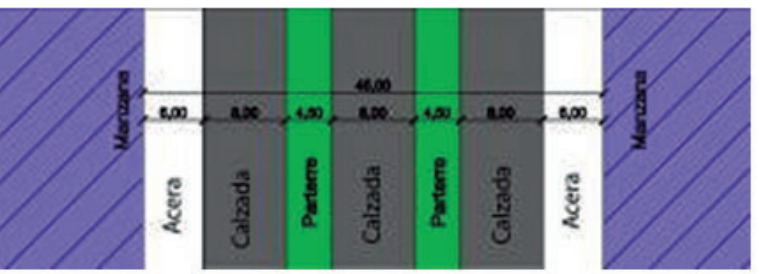

Avenida de $45 \mathrm{mts}$ y parterre de $4.50 \mathrm{mts}$

Las avenidas de la ciudad se caracterizan por tener bulevares amplios con suficiente superficie verde donde las especies arbóreas pueden subsistir adecuadamente, mientras se respete las normativas vigentes para su cuidado y para el uso de estos espacios, y no como en algunos sectores en donde son utilizados como estacionamientos de motos $u$ otros vehículos, dañando la superficie verde dejando una estética no muy bien vista.

La trama urbana de la ciudad esta conformada por una sucesión de manzanas de $100 \times 100$ metros a modo de damero, su uso esta reglamentado según el distrito de zonificación de cada una de ellas, en donde se estipula el porcentaje construible en las parcelas que contengan estas manzanas, como así también las características que deban poseer para el buen desarrollo territorial de la ciudad. (Fig.4).

Las medidas normales de las calles como ya se señalara (refiriéndonos siempre al área en estudio) son de 20 metros desde línea municipal a línea municipal. De acuerdo a normativa, $8 \mathrm{~m}$ corresponden a las calzadas, y $6 \mathrm{~m}$ de acera a cada lado. 


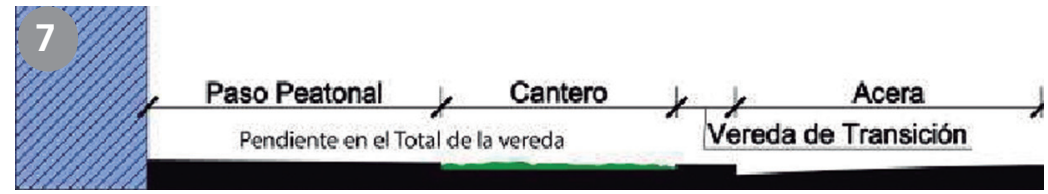

Sin embargo de acuerdo al relevamiento realizado estas dimensiones no se cumplen en todos los casos. En las avenidas estas medidas cambian, llegando a poseer de línea municipal a línea municipal alrededor de 30 a 45 metros aproximadamente. Como se explicara, las de 30 metros son las avenidas que conforman el anillo central interno y las de 45 metros las del segundo anillo, es conveniente aclarar aquí, que las medidas cambian por agregársele al caso anterior uno o dos carriles mas, para el transito vehicular, mas el bulevar o parterre en su centro separando a éstos.

El parterre es de ancho variable y depende de la cantidad de carriles que posea la avenida.(Fig.5).

Analizando ahora las veredas, y como bien se puede distinguir en los gráficos anteriores, la misma posee un ancho estándar de 6 metros, el cual esta subdividido de la siguiente manera: (Fig. 6)

Para el escurrimiento y absorción de aguas de lluvia, las veredas en general, como los canteros tienen su manera correcta y lógica de materializarse; deben tener una pendiente ínfima que no llegue a molestar el paso del peatón pero si que permita el fácil deslizamiento de las aguas de lluvia principalmente. El cantero no debe poseer bordes que superen el nivel superficial de las veredas, para que el agua que venga escurriéndose pueda tener libre paso hacia éste para su absorción en terreno natural, de esta manera no se saturan los desagües de la ciudad, evitando así el anegamiento de las calles. (Fig. 7).

\section{CARACTERÍSTICAS GENERALES DEL ARBOLADO URBANO DE RESISTENCIA}

..."Una persona que visite Resistencia, y transite en veranos con temperaturas superiores a los $35-40^{\circ} \mathrm{C}$, se $d a$ cuenta en forma inmediata que es necesario contar con abundantes árboles para encontrar frescura y bienestar. Si bien muchas personas están acostumbradas a la rigurosidad de nuestro clima, también es cierto que aprecian las bondades y los beneficios que aportan los árboles" (RUCHESI, 1999).

El arbolado ha ido perdiendo lugar, junto con los espacios verdes, llegando solo al $0.81 \mathrm{~m}^{2}$ por habitante, cifra que esta muy por debajo de los que aconseja la O.M.S. que es de 10 a $15 \mathrm{~m}^{2}$. Hay que tomar conciencia de la importancia de los espacios naturales dentro de la cuidad donde la perdida de superficie verde va en crecimiento, y donde los intentos por frenar este índice son cada vez mayores pero vanos, al interesarle solo a un porcentaje pequeño de la población, y esto no es trabajo solo de unos pocos ya que a la cuidad la construimos entre todos, y en esta construcción es de fundamental importancia tener presente el espacio verde como factor regulador de la misma.

Los paisajes de la ciudad poseen una belleza estética muy agradable, las manchas de colores en las estaciones de floración de los lapachos, tipas, chivatos entre otros, brindan sensaciones distintivas muy apreciables; que definen la identidad de Resistencia, sin embargo estos valores agregados del espacio publico están yendo en declive y las especies que mas favorecen al estado ambiental y paisajístico van desapareciendo por no tener mantenimiento en algunos casos o solo porque se introducen especies nuevas que no son autóctonas, que ofrecen solo el factor estético como relevancia, aportan nada al ambiente natural y su equilibrio.

..."En zonas de buen poder adquisitivo, se utilizando palmeras o arbustos de porte bajo o rastrero, privilegiando solo es aspecto estético ya que no quieren ocultar la fachada de las lujosas viviendas. Las áreas suburbanas y periféricas caracterizadas por numerosos barrios que se formaron en los últimos 20 años, están desprovistas de árboles. Las características de los suelos 


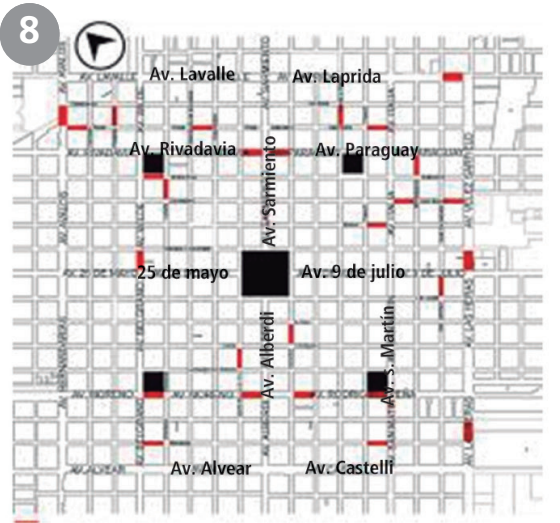

\begin{tabular}{|c|c|c|c|c|c|c|c|}
\hline \multirow{4}{*}{ 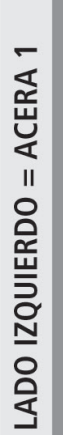 } & \multirow{4}{*}{ 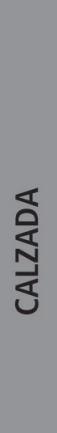 } & \multirow{4}{*}{ 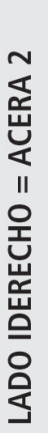 } & & $\begin{array}{c}\text { CANTIDAD DE } \\
\text { ÁRBOLES }\end{array}$ & $\begin{array}{l}\text { CANTIDAD DE } \\
\text { ESPECIES DE } \\
\text { ÁRBOLES }\end{array}$ & $\begin{array}{l}\text { SUPERFICIES DE } \\
\text { CANTEROS } \\
\text { (espacios verdes) }\end{array}$ & $\begin{array}{l}\text { ESTADO DE } \\
\text { CANTERO }\end{array}$ \\
\hline & & & ACERA 1 & $\begin{array}{c}12 \text { un. } \\
\text { aconsejables }\end{array}$ & & $\begin{array}{c}158 \mathrm{~m}^{2} \\
\text { aconsejables }\end{array}$ & \\
\hline & & & ACERA 2 & $\begin{array}{c}12 \text { un. } \\
\text { aconsejables }\end{array}$ & & $\begin{array}{c}158 \mathrm{~m}^{2} \\
\text { aconsejables }\end{array}$ & \\
\hline & & & $\begin{array}{c}\text { TOTAL } \\
\text { CUADRA }\end{array}$ & 24 un $\times 100 \%$ & & $316 \mathrm{~m}^{2} \times 100 \%$ & \\
\hline
\end{tabular}
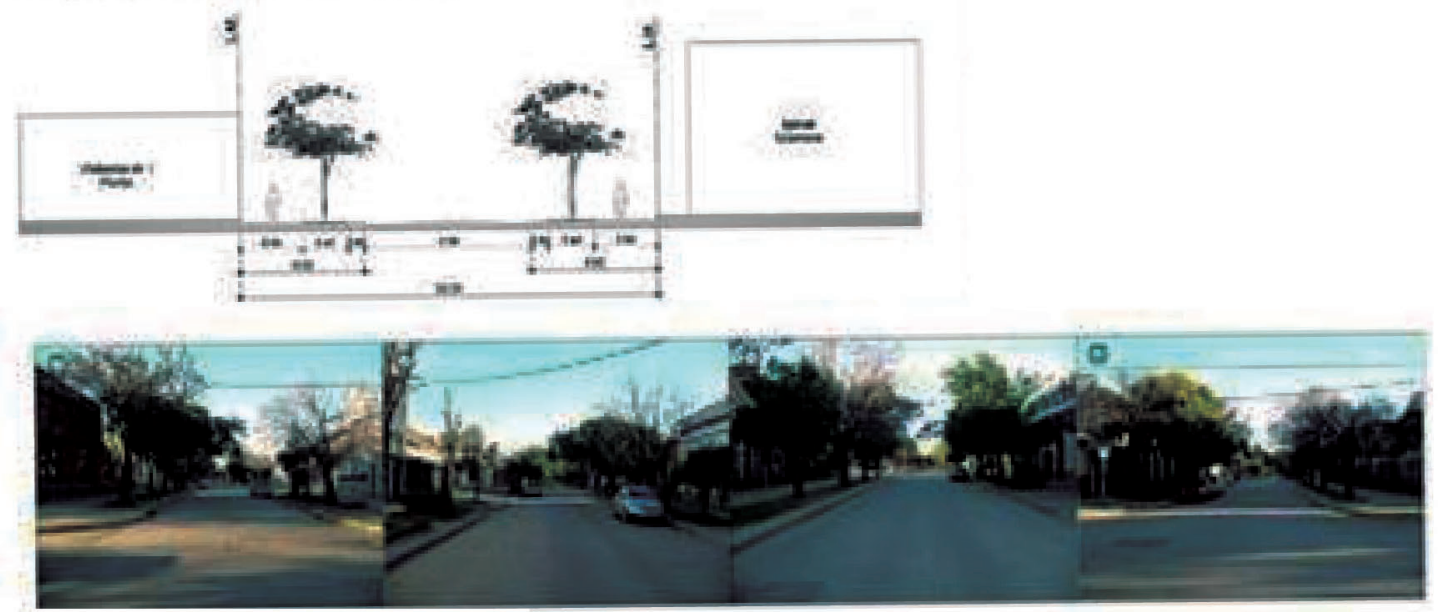

Fecha/ Estación: junio 2011 - otoño

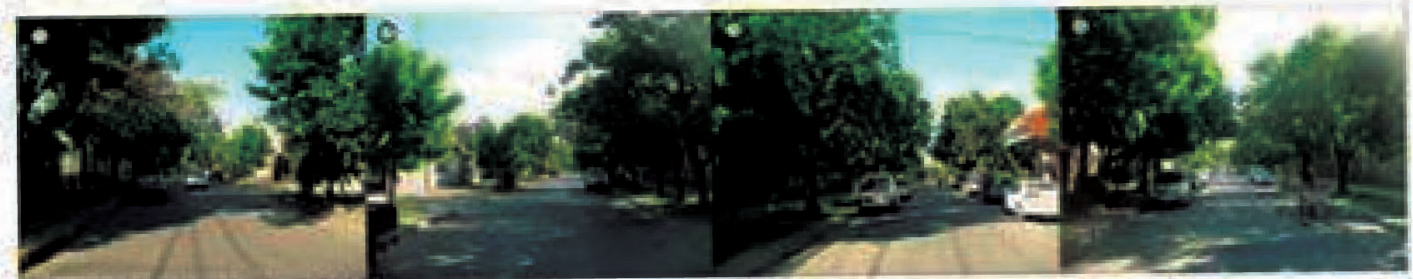

Fecha/ Estación: noviembre 2011 - primavera

Referencia árboles

19. Fresno

Acacia

CALLE Liniers

Relevamiento $\mathrm{N}^{\circ} 3$

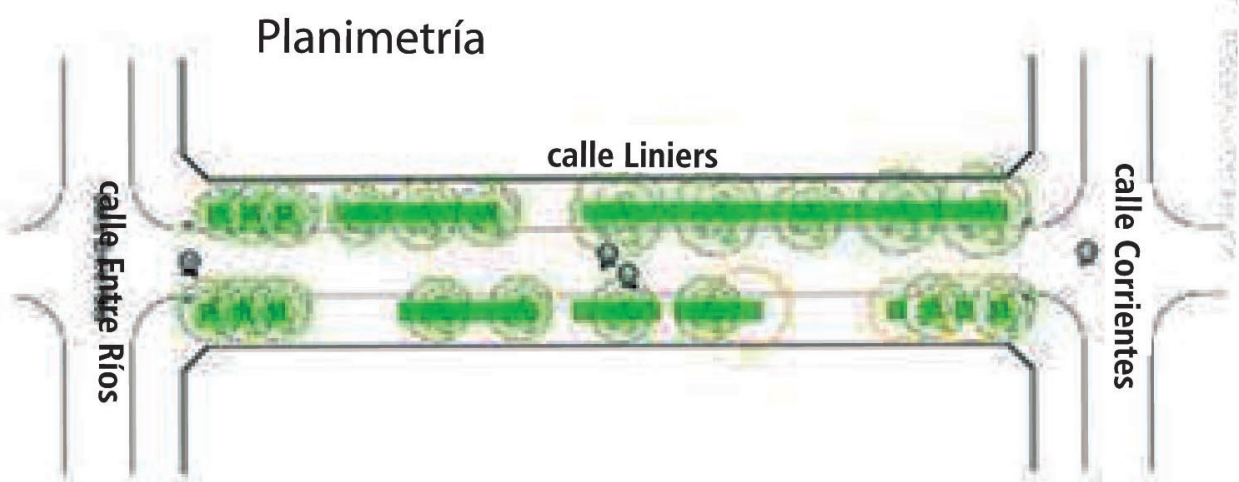


10. Tipificación de ejes según su aporte

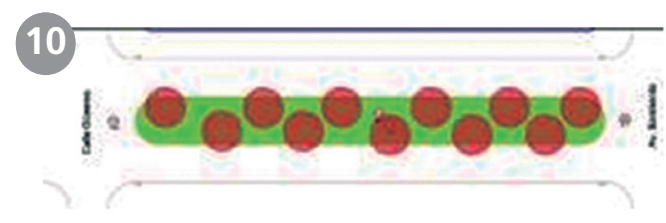

Eje con árboles de porte grande

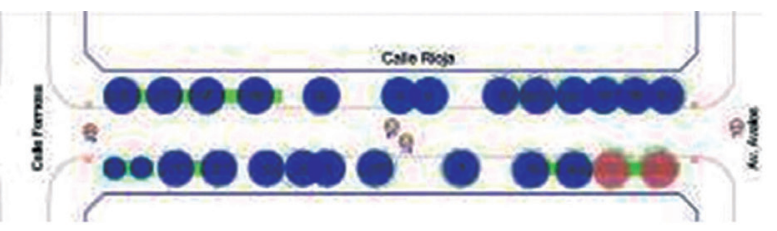

Eje con árboles de porte mediano

Arbol de porte chico Árbol de porte medio

Árbol de porte grande

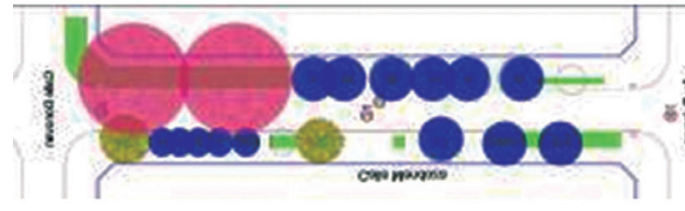

utilizados para rellenar estos asentamientos, y los tratamientos de compactación que han recibido no permiten que prosperen la mayoría de las especies arbóreas, haciendo fracasar los intentos de los vecinos en reiteradas oportunidades". (RUCHESI, 1999)

\section{SISTEMATIZACIÓN DE CALLES RELEVADAS}

En el plano general aparecen ubicados los veintisiete ejes relevados marcados en color rojo, para poder referenciarlos con respecto a la ciudad y su distribución dentro de la misma.

A modo indicativo a las aceras también se les dio nombres, estando siempre del lado izquierdo la Acera uno y del lado derecho la Acera dos, esto realizado a fin de generar un cuadro en donde aparezcan en cada una diferentes datos de interés.

En este cuadro también aparecen informaciones tales como; cantidad de arboles, que tomando los datos sugeridos por el Ing. Agr. José A. Ruchesi.en su Tesis en Maestría en Gestión Ambiental y Ecológica.

Propuesta y ordenación del arbolado urbano de la ciudad de Resistencia, son de doce por lado acera como mínimo, existiendo un total de veinticuatro por cuadra, dado que las dimensiones de las aceras lo permiten y debido a que las características climáticas y urbanas de la Ciudad así lo requieren para darle a la zona un buen y mejor desarrollo ambiental.

La cantidad de tipos de especies arbóreas, la superficie destinada a canteros y el estado de los mismos, son información útil a tener en cuenta, ya que también mediante esto la ciudad posee diferentes beneficios, como la estética, según la especie arbórea plantada y sus cambios en las diferentes estaciones; la superficie existente en canteros actúan como retenedores del agua de Iluvia y si el estado de estos es correcto se potencia su uso, etc.
Este cuadro también nos servirá para analizar los ejes relevados y tener una noción más exacta de estos, reconociendo cualidades y problemas existentes. (Cuadro 8 y 9).

\section{TIPOLOGÍAS DE CALLES SEGÚN SU ARBOLADO}

Cuando tipificamos los ejes relevados por su arbolado, lo hacemos de acuerdo al impacto que tienen estos sobre el observador, impacto que lo provoca la presencia de las copas, de los colores y olores y las mezclas de estos en los recorridos, que dotan de una belleza diferente a los diversos sectores de la ciudad.

Las tipologías encontradas se expondrán de manera ejemplificativa y esquemática de las cuales se sacaran valores aproximados en porcentajes sobre la cantidad de los relevamientos, para poder entender mejor el estado del arbolado en la ciudad y de sus características más relevantes.

\section{TIPIFICACIÓN MEDIANTE SU PORTE}

En este caso se encontraron cuatro maneras de ejemplificar los ejes a través de su porte:

De Porte Grande: con el 6,66\% de los ejes relevados, por ejemplo la Av. Paraguay con sus grandes grevielas, y la Calle Moreno a la altura de la Plaza 9 de julio con sus tipas, arboles de gran porte que necesitan de gran espacio para poder crecer y desarrollarse.

De Porte Medio: con un valor del $46,66 \%$ sobre la totalidad relevada, ejemplos: Av. Moreno entre Sta. María de Oro y Av. Alberdi; Rioja entre Av. Avalos y Formosa, etc. 
11. Avenida Wilde

12. Avenida Laprida
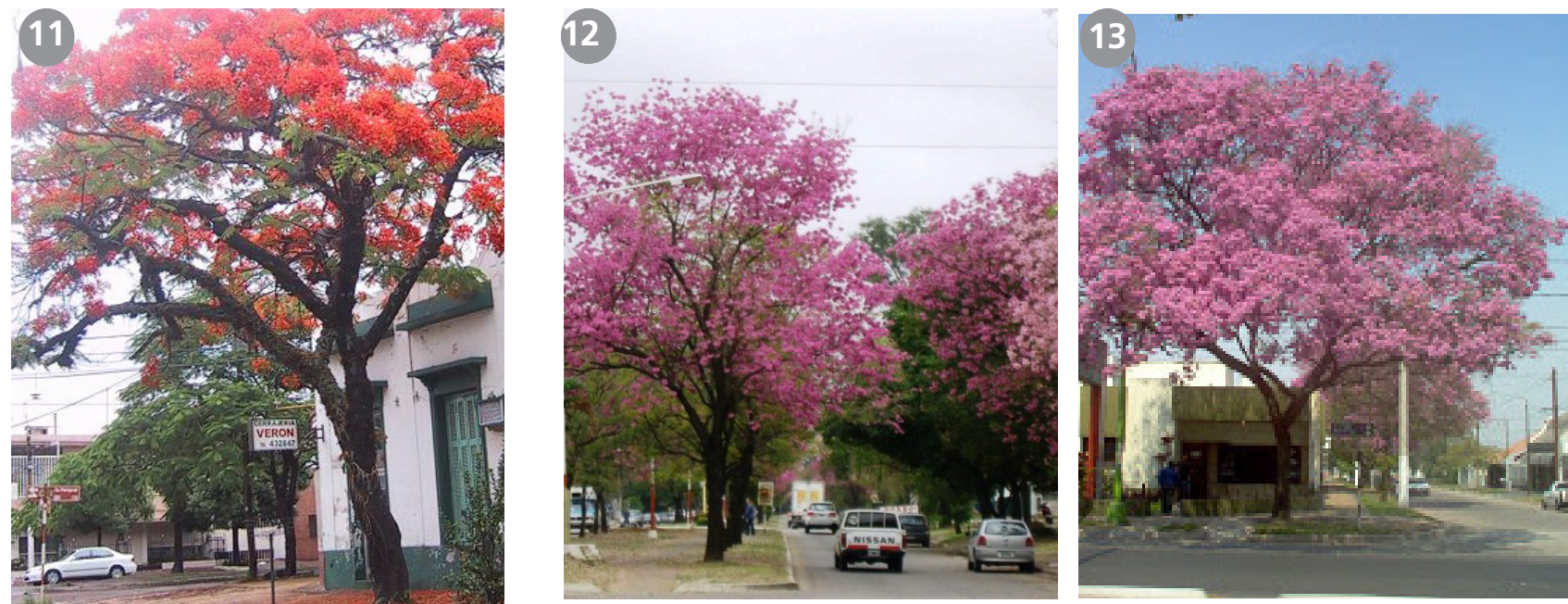

13. Avenida Las Heras
De Porte Mixto: son aquellos ejes en donde conviven árboles con diferentes tipos de porte ya sean grandes, medianos y pequeños con cantidades variables, distribuidos de manera espontanea sobre la superficie destinados para ellos.

El porcentaje de estos son del $46,68 \%$ y algunas calles ejemplificativas son Mendoza entre Av. Belgrano y Dónovan; Calle Posadas entre Catamarca y Rioja; Saavedra entre Av. Italia y French; etc.

Esta tipología de eje es muy importante y a tener en cuenta ya que si se colocan de manera correcta la distribución de los arboles de diferentes portes sobre la longitud de cada calles, se logra generar pantallas, las cuales ayudan a mitigar el sonido que ingresa a los edificios, como así también brindan protección contra los vientos perjudiciales, entre otras cosas. (Fig. 10).

\section{TIPIFICACIÓN SEGÚN SU FLORACIÓN}

En el relevamiento se encontraron en la mayoría de las calles especies de floración, y se las clasifico en calles con arbolado con floración y calles con arbolado sin floración, existiendo para los primeros un valor en porcentaje de $73,33 \%$, mientras que el $26,67 \%$ restante correspondería al segundo caso.

Alguno ejemplos de calles con arbolado con floración serian el caso de la Av. Vélez Sarfield entre 9 de Julio e Irigoyen, la Av. Rodriguez Peña entre Calle J.M. Paz y Colon, Calle Brown entre Av. Italia y French, etc., mientras que los casos en donde se hallan recorridos con arboles sin floración serian la calle Saavedra entre Av. Italia y French, calle Rioja entre Av. Avalos y Formosa, entre otras. (Imágenes 11,12 y 13).

\section{TIPIFICACIÓN SEGÚN PÉRDIDA DE FOLLAJE}

La pérdida del follaje en los árboles modifica la temperatura e impiden o no el libre paso de los rayos solares que ingresan a los edificios o que se proyectan en la superficie del espacio público.

Esto puede ser de gran ayuda en alguna estación del año, por ejemplo en periodos de baja temperatura si encontramos arboles sin follaje, ayudaría a contrarrestar el frio al ingresar más rayos de sol y por consiguiente mayor temperatura, esto sucede pero en sentido inverso en temporadas de mucho calor, en donde la copa de los arboles al proyectar sombra refrescan el ambiente.

En la cuantificación de este tipo de ejes se encontraron un total de $37 \%$ de Ejes con árboles hojas caducas y el $63 \%$ restante son Ejes con árboles de hojas perenes. Ejemplos de los primeros son las Calles Posadas entre Catamarca y Rioja, Liniers entre Corrientes y Entre Rios, Entre Rios entre Liniers y Av. Wilde, etc. (Fig. 11, 12 y 13).

\section{PROBLEMAS DESTACADOS}

En el relevamiento se han encontrados diferentes problemáticas a recalcar y a tener en cuenta en los ejes, por ejemplo en un $75 \%$ de casos no se respeta la superficie destinada ni la correcta materialización de los canteros, como así tampoco la correcta plantación de la cubierta verde, perjudicando con ello la capacidad de absorción de las aguas de lluvia, así también la cantidad de árboles no son las suficientes lo que recae en una calidad ambiental regular preocupante. 
14. Calle Liniers

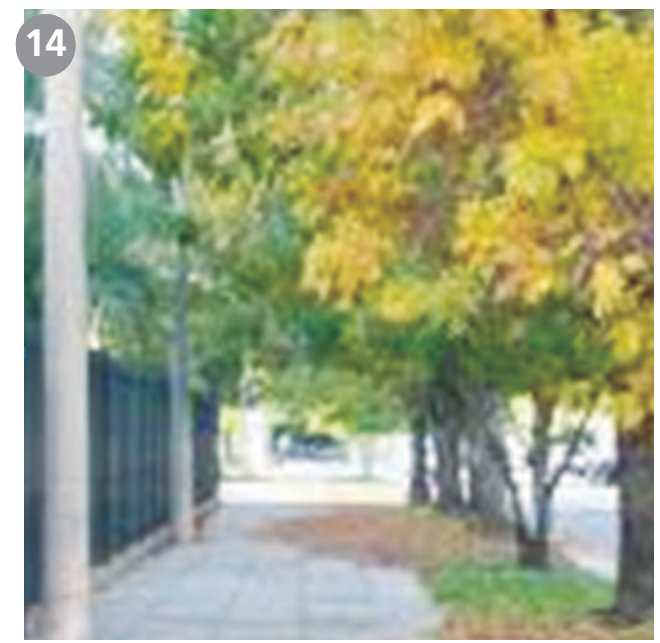

\section{CARACTERÍSTICAS \\ DE INTERÉS A POTENCIAR}

Si bien el arbolado urbano de la ciudad de Resistencia esta en un estado de degradación, por carecer de un numero adecuado de especies y de espacios verdes en sus recorridos, el aporte y las características que brindan los existentes es relevante al momento de readecuar las zonas degradadas del espacio publico, porque estos en su espontaneidad le dan a la ciudad beneficios estéticos como ambientales, y el cuidadoso manejo de los mismos potencian estas virtudes y mejoran la calidad de vida de sus pobladores.

Las dimensiones de los espacios verdes superficiales en las aceras y corredores estudiados brindan un medio adecuado para que los árboles se desarrollen perfectamente, esto claro si están bien diseñados y respetando siempre las reglamentaciones impuestas para el espacio publico detalladas en el Código de Planeamiento Urbano de la Ciudad y el Reglamento de Construcción.

Estos espacios permiten tener suficientes especies arbóreas que mejoren la calidad ambiental de Residencia, como así también una buena organización de estas permiten resaltar la estética del paisaje urbano, como ya se menciono mas arriba.

El espacio destinado a los canteros permite retener las aguas de lluvia favoreciendo la gestión hídrica de la zona en temporadas de precipitaciones, ayudando al rápido escurrimiento de estas.
15. Calle Corrientes

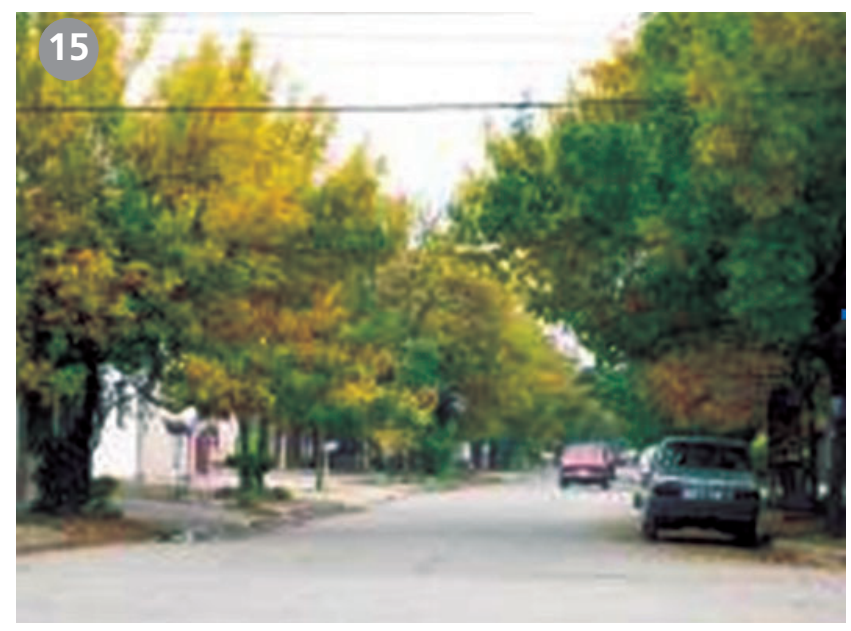

\section{RESULTADOS, CONCLUSIONES Y/O REFLEXIONES FINALES}

El arbolado urbano de la ciudad ofrece un paisaje muy apreciable estéticamente tanto para el visitante como para el que reside en la misma, pero que con el devenir de los años este paisaje ha ido sufriendo modificaciones que alteraron su morfología y calidad, reduciendo así la eficacia ambiental y su belleza natural; esto debido a que no se trabaja en conjunto con las diferentes entidades relacionadas ni con los expertos en el tema.

El municipio no ejerce el poder de policía para controlar el cumplimiento de las normativas vigentes para la correcta materialización de las aceras, lo cual recae en la disminución de ejemplares de especies arbóreas que debe existir en la trama urbana y por consiguiente en el deterioro paisajístico - ambiental.

Si tomamos la verdadera magnitud de lo que el árbol y el verde en el espacio publico ofrece a la ciudad y a la vida de los ciudadanos nos daríamos cuenta de que la presencia de estos recae en el bienestar personal y psicológico de nosotros mismos al brindarnos una ciudad cambiante en el sentido paisajístico con un buen desarrollo ambiental. 


\section{BIBLIOGRAFÍA}

Aguirre Madariaga, Eduardo. Gestión para incorporar al Plan Estratégico de la ciudad de Resistencia la propuesta de Puesta en Valor de la Plaza 25 de Mayo de 1810 con su entorno inmediato y el resto de la ciudad a través de la conformación de un Sistema de Espacios Verdes. Director: Sonia Berjman. Resistencia: Universidad Nacional del Nordeste.2007. Tesis de Maestría en Gestión del Ambiente, el Paisaje y el Patrimonio.

Marengo De Tapia, Martha. Los árboles y el paisaje. Usos, Formas y escalas. Serie Ediciones Previas. FADU- UBA. Buenos Aires

Ruchesi, José Alberto, 1999. Propuesta de ordenación del arbolado urbano de la ciudad de Resistencia. Tesis de Maestría en Gestión Ambiental y Ecología. UNNE

Secretaría Distrital De Ambiente, 2011. Arbolado urbano de Bogotá: identificación, descripción y bases para su manejo 